this being the first record of the genus south of the equator in the Eastern Hemisphere-seven specimens were taken, all, unfortunately, females.

The results of this expedition are evidently such as to encourage the Colonial Government in continuing the work, as Mr. Waite has been able, not only to add to scientific knowledge, but to obtain much information directly bearing on the fisheries. If all of our Sea Fishery Districts Committees were to combine in carry ing on similar operations round our own coast, notable progress would be made towards obtaining that approxi. mate "census" of our territorial waters which is required for the solution of both scientific and economic problems.

W. A. HFRIDMAN.

\section{THE ORIGIN AND OCCURRENCE OF CAVE-ICE.}

A LTHOLGH ice-caves and their phenomena present some of the most interesting problems in the whole range of physical geography, it is singular to note how comparatively little attention has been directed to their investigation, and how inadequate still is the sum total of observation and experiment hitherto carried out, for the full elucidation of the many questions which arise in connection with their study. A recent investigator in this field of research is Dr. Hans Lohmann, who, in an admirable treatise on cave-ice ("Das Höhleneis unter besonderer Berücksichtigung einiger Eishöhlen des Errgebirges," Jena, 1895), has brought together the results of previous work on the subject, and incorporated an account of his own observations in the ice-caves of Saxony. It is here only possible to set forth in the merest outline some of the more interesting facts connected with these natural ice-stores, and to indicate in brief the theories that have been advanced to account for some of their phenomena.

Ice-caves have been defined as natural or artificial cavities in the earth, in which ice, formed within them, is preserved either the whole year round or for a greater part of it. They may be roughly divided into two classes, termed by 'Thury "static" and "dynamic," or, according to Fugger, the ice-caves properly speaking and the "wind passages." The first are blind caves with only a single outlet, while the caves of the second class have connection by passage or cleft between their inner end and the outside air at some point in the hillside higher than the main entrance. Almost all known ice-caves are situated in the north temperate zone (roughly, between $40^{\circ}$ and $60^{\circ}$ ), and the feur exceptions which lie nearer the equator are so highly situated that in winter the temperature within them falls below the freezing point. Generally speaking, the caves do not lie in high mountain regions, though all are located where snowfall is possible.

The causes which bring about the formation of the ice are to be looked for solely in the meteoroloyiral and climatic conditions of the localities in which the caves occur. In the case of blind caves, the floor of the cavity is situated at a lower level than that of the entrance, and when the outer atmosphere becomes cooled below the temperature of the inner air, the former, by reason of its greater density, sinks into the cave, slowly displacing the contained air and thus giving rise to an air-current which brings about the chilling of the cave. When the outside temperature rises, that of the cave begins to rise also, but only slowly at first, because the warmer outside air possessing a smaller specific gravity can no longer sink into the cave, and the heat is conducted to the interior very slowly. During such periods (the "closed periods" of Trouillet) a temperature curve, shown by a registering thermometer placed within the cave, assumes the form of an almost straight line. The inner temperature Nง. I 590, vOL. 6I] then lingers for a long time in the neighbourhood of the freezing point, but rises again with comparative rapidity when all the contained ice is at last melted.

The cold produced by evaporation within the cave also tends to lower the temperature, and in those ice-caves classed as "wind passayes" the influence of evaporation in this direction is very marked. While in summer the air contained in the blind caves is perfectly still, a strong air-current is found to prevail at this season in the windpassages. It has been observed that when the outer teniperature was considerably higher than that within, the wind-stream was passing outwards; at such time as the inner and outer temperature were alike, the current was intermittent or not observable; but when the outer temperature was lower than the inner, the draught was passing inwards. In such cases we have two separate air columns of equal height, one situated within the mountain, the other formed by the outer atmosphere. As soon as a difference of temperature in the two columns is brought about, the tendency to restore equilibrium gives rise to the air-current through the cave, as a result of which the latter becomes cooled in the winter and gradually warmed during the summer. But the downward current which prevails in summer may sometimes bring about a considerable cooling within the cave through cvaporation, and if the outer air be very dry the formation of ice may even take place. Systematic observation has made it clear that the potent factor in the production of ice within the caves is the air-current.

The ice itself, formed principally during the spring-time, when the conditions of temperature and water supply are most favourable, is distributed in a varying manner; it may clothe the floor, the walls and the roof as a closefitting sheet, or may hang in curtain-like form from the roof, or give rise to the formation of ice-stalactites and stalagmites, according to the distribution and manner of the water supply from above.

In connection with the thawing of ice-stalactites, an interesting phenomenon may sometimes be observed. Since the collecting point of the drip which gave origin to the stalactite is situated in the centre of the base of the latter, the thawing action of the water from above may proceed in such a way as to eat out the centre of the stalactite, leaving its peripheral parts hanging as a mere shell or tube. This has been explained by the fact that the warmer water introduced, having a yreater specific gravity than water at the freezing point, will tend to sink to the base of the little hollow formed at the root of the stalactite as a first result of thawing, and thus rapidly carry out its work as a vertical borer.

But perhaps the most interesting phenomenon exhibited by cave-ice, to the description and elucidation of which Dr. Lohmann has devoted special attention, is the peculiar structure known as the "prismatic" or "honeycomb" structure. At certain times the surface of the ice is found to be broken up by a net-like system of fine crevices, resulting in the production of meshes of varying and more or less irregular form. It has been found that, strictly speaking, this structure does not appear during the winter, nor does its formation occur in all cases at the same time of the year. While in some caves this splitting process has never been observed to take place before the end of August, the ice in the caves of Saxony have exhibited the structure in an advanced stage as early as the month of March. The size of the meshes is very variable, and they may reach dimensions so great as 400 square centimetres, or be so minute as to be observed with difficulty by the naked eye. The crevices may be merely superficial, or may penetrate the ice to a depth of several centimetres, there to cease abruptly, and thus give rise to a superficial "prismatic layer" sharply separated from the compact ice beneath. But the development of honeycomb structure often proceeds so far that a thin ice-sheet is completely penetrated 
by the net system, in which case the meshes on either surface of the ice-plate are of equal size.

As to the explanations which have been offered to account for the formation of the honeycomb structure, no theory seems to have been recently proposed which is not based upon that of Robert Emden, who supposed

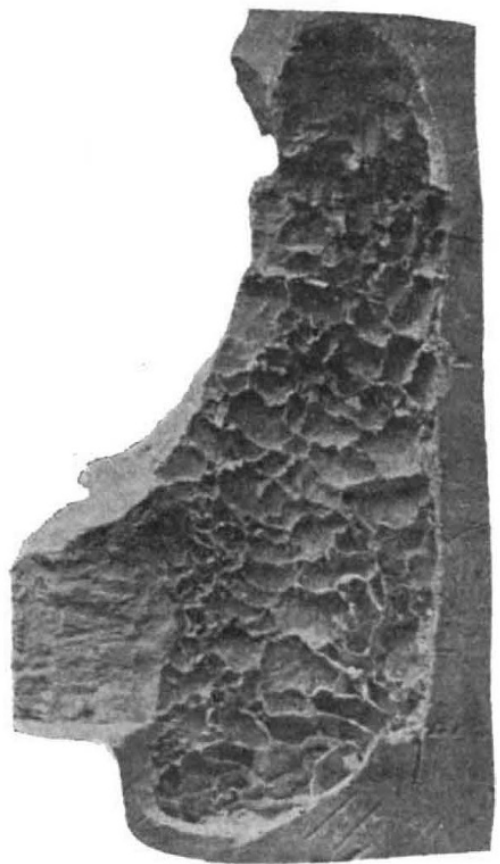

FIG. I.-Structure of exposed surface of wall-ice.

that in all ice masses exposed for some time to a temperature neighbouring on the freezing point, the minute first-formed crystals, even when possessing an irregular original arrangement, tend to undergo a complete rearrangement, and to form crystal units of ever-increasing size, having similarly directed axes. The dimensions to which these new crystal units will attain is determined by the temperature variations. Should the temperature rise and a thaw set in, those portions of the ice where the individual crystals are in contact with one another will be the first to be attacked, and the melting process will produce the appearance of the net system.

Since the rock in which the caves or drifts are formed always possesses a somewhat higher temperature than the air within the cavity, the coalition of the individual ice crystals in contact with the cave wall will take place at a somewhat earlier period than that of the crystals on the exposed surface of the wall-ice, for the inner side will be sooner raised to a temperature closely approaching the freezing point. But in like manner, as the general temperature rises, the inner surface of the wall-ice will become exposed to the action of actual thawing earlier than the free outer surface, and the development of the growing crystal units - the groundwork for the "cells" of the honeycomb structure--will receive an earlier check on the inner surface than on the free surface. This explanation has been given to account for the fact that the meshes in contact with the rock are smaller than those exposed to the cave air, as shown in the accompanying illustrations reproduced from Dr. Lohmann's paper, for which photographs were obtained from plaster casts of the ice surfaces.

But Emden's theory, as briefly sketched above, does not seem to explain certain facts observed in connection with the "prismatic" structure shown by some forms of ice. The peculiar form of the network developed, for instance, on the surface of an ice-stalactite, with its radially arranged tiers of "cells," requires further explanation. Lohmann ascribes an important part in determining the arrangement of the "cells " to the expansion and contraction of the ice under changes of temperature. Since the coefficient of expansion of ice is great, the surface when exposed to variations of temperature will undergo a splitting process, which will result in the production of so-called "elementary cells." These will then become crystal units (if not already such) by the process of coalition which Emden supposed to occur, and the ultimate dimensions of the prismatic structure are then

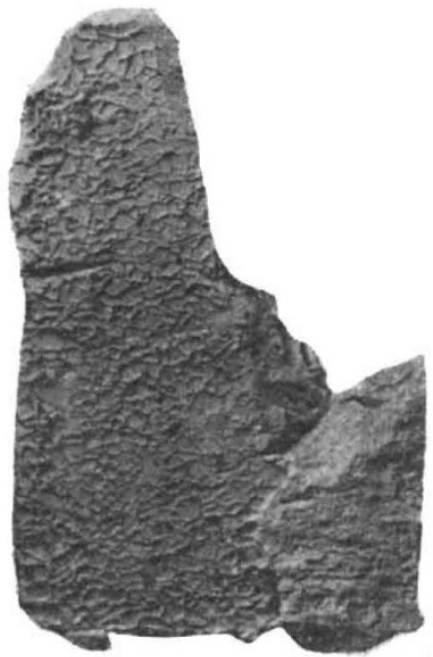

FIG. 2.-Structure of ice surface in contact with rock

finally determined by a rise of temperature, forming spaces between the "cells" as above indicated. But while this improved theory seems to offer a fuller explanation of the observed facts, final proof of its value as a sound hypothesis is only to be sought in the evidence of further experimental investigation.

$$
\text { F. L. K. }
$$

\section{NOTES}

Prof. A. A. Mrchelson, professor of physics in the University of Chicago, has been elected a correspondant of the Paris Academy of Sciences.

The first meeting of the International Conference for the Protection of Wild Animais in Africa will be held at the Foreign Office on April 24. The British representatives will be the Earl of Hopetoun, G.C.M.G., Sir Clement Hill, K.C.M.G., C. B., head of the African department of the Foreign Office, and Prof. Ray Lankester, F.R.S., director of the Natural History Museum.

To encourage the study of aërial navigation, a member of the Aéro Club of Paris has given the sum of 100,000 francs, to be awarded as a prize to the inventor of an efficient aërial machine. The test to be applied is that the machine shall travel from the grounds of the Club, or from the hills of Longchamps, to the Eiffel Tower, and then to return to the starting point. The length of the whole journey is about eleven kilometres, and it has to be accomplished in half an hour or less. The competition is international, and the offer will remain open for five years from the middle of the present month. The interest upon the sum placed at the disposal of the Club will be awarded annually for

NO. I 590, VOL. 6I] 